\title{
Experimental and Simulation investigations of Micro Flexible Deep Drawing Using Floating Ring Technique
}

\author{
Zaid H. Mahmood* Ihsan K. Irthiea** Kadum A. Abed ${ }^{* * *}$ \\ *,**,***Department of Mechanical Engineering/ College of Engineering/University of Anbar/ Anbar/ Iraq \\ *Email: zaid_eng88@yahoo.com \\ **Email: ih77san@yahoo.co.uk
}

(Received 30 August 2017; accepted 26 December 2018)

https://doi.org/10.22153/kej.2018.12.007

\begin{abstract}
Micro metal forming has an application potential in different industrial fields. Flexible tool-assisted sheet metal forming at micro scale is among the forming techniques that have increasingly attracted wide attention of researchers. This forming process is a suitable technique for producing micro components because of its inexpensive process, high quality products and relatively high production rate. This study presents a novel micro deep drawing technique through using floating ring as an assistant die with flexible pad as a main die. The floating ring designed with specified geometry is located between the process workpiece and the rubber pad. The function of the floating ring in this work is to produce SS304 micro cups with profile radius precision as required as possible. The finite element simulations are accomplished using the commercial code Abaqus/Standard. In order to verify the simulation models, micro deep drawing experiments are carried out using a special set up developed specifically to meet the requirements of the simulations. The results revealed that the proposed technique is feasible to be adopted for producing micro cups with remarkable application capability in miniaturization technology.
\end{abstract}

Keywords: Flexible tool, micro deep drawing, finite element simulation, floating ring.

\section{Introduction}

The increasing demand on micro parts utilized in various industrial fields, including electronics and micro-medical devices get the manufacturers into a competitive situation [1]. Therefore, using advanced manufacturing processes and innovative techniques has significantly become urgent need for technology advancement [2]. Recently, sheet metal forming using flexible tools is one of the forming techniques that attract great attention of many researchers. Flexible tool-assisted sheet metal forming can be characterized by its feasibility for prototyping processes, simplicity and versatility. In comparison to conventional deep drawing, flexible tool-assisted deep drawing has many other advantages such as better surface quality, better dimension accuracy, capability for complex shaped parts and lower production cost
[3, 4]. F. Quadrini et al. [5] studied the effect of die material and its geometry on forming processes of aluminum sheet metal with thickness $150 \mu \mathrm{m}$. The dies used were rigid, silicone rubber, styrene butadiene rubber and polyamide 66 . The results showed that using semi-rigid die contribute in production improvement in terms of forming force reduction and die durability. Flexible Pad Laser Shock Forming (FPLSF) process was presented by Nagarajan B. et al. [6] to investigate the influence of flexible pad material and its thickness, on the deformation characteristics of different metal foils. It was observed that using rubber material with higher hardness resulted in a reduction in crater depth, foil thickness and the hardness of the crater surfaces. However, increasing the flexible pad thickness resulted in an increase in crater depth, thinning but a reduction in surface hardness. Y. Liu et al. [7] used rigid 
dies with two different designs, concave and convex, with flexible pad to produce micro channels. The results showed that the concave design of die more suitable to fabricate micro channels and however thickness reduction in convex design was decreased with increasing aspect ratio value. C. Jin et al. [8] studied the effect of rubber pad properties, speed and pressure of punch on forming behaviour of different sheet metals, stainless steel 304, aluminum 1050 and titanium. The results demonstrated that the depth of the micro channels can be increased by using softer rubber or increasing any of rubber thickness, punch speed and punch pressure. I. Irthiea et al. [3] proposed a new technique for forming micro cups from stainless steel 304 sheets with different initial thicknesses using flexible pad. Many process parameters were studied in this work such as anisotropy of SS 304 material, initial gap, friction conditions at various contact interfaces and initial sheet thickness. This study proved that the interaction among the adopted parameters result in producing successful micro cups with high aspect ratio and high quality. Wang at el. [9] introduced a novel laser dynamic flexible forming technique through experiments and numerical simulations. The results showed that increasing the thickness of the soft punch leads the depth of the formed sheet to decrease. Also, as the pulse energy increases the deformation depth increase as well. The deep drawability of ultrafine grained copper sheet of $0.4 \mathrm{~mm}$ thickness was studied by Ma et al. [10] using the method known Equal Channel Angular Pressing (ECAP) for various ultrafine grained microstructure. It was obtained minimum limit drawing ratio with one ECAP pass and increasing the number of passing caused a slight increase in the limit drawing ratio. The same observation was pointed by Lapovok et al. [11] in a study achieved on ultrafine grained aluminum sheet.

This work presents a novel flexible toolassisted micro deep drawing process (FTAMDD) of stainless steel 304 foil using polyurethane rubber ,55 shore A hardness, as forming die with floating ring technique. The circular blanks used as process workpieces were cut from SS 304 foil of $100 \mu$ with $10 \mathrm{~mm}$ diameter. The novelty point of this study is to use a floating ring part, as assistant die, in cooperating with flexible die to produce micro cups with high quality in terms of wall thickness and dimensions. The finite element simulations were built using the commercial code Abaqus/Standard. Serious of micro deep drawing experiments were implemented to validate the FE models. The main purpose of this work is to evaluate the feasibility of the proposed technique in miniaturization technology. There was observed a good correlation between the simulation and experimental results in terms of final cup shape, thickness distribution, punch force and maximum reduction in thickness.

\section{Proposed Methodology (Innovative Technique)}

In the proposed technique, the forming process is divided into three main steps to obtain complete micro cups. In the first step, the forming depth will be equal to the floating ring thickness where the lower face of workpiece will be just get into direct contact with the rubber pad surface. In the second step, the solid punch will keep pushing the shallow-formed blank into the flexible die, generating a hydrostatic pressure in the rubber material. This action will basically result in forming both the sheet blank and rubber die simultaneously.
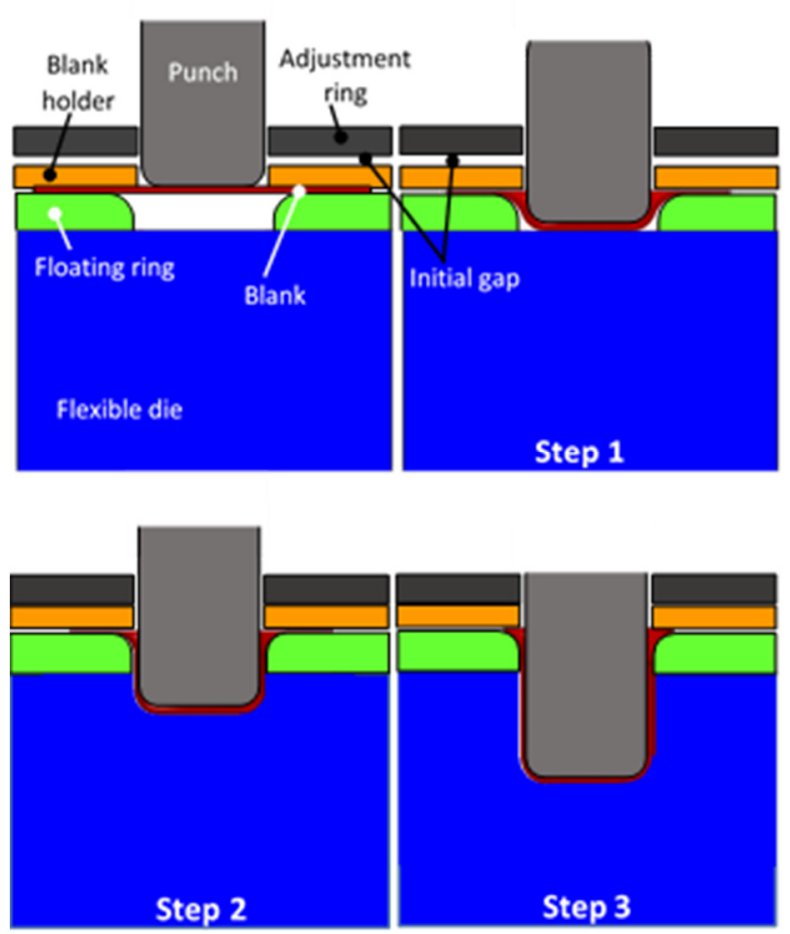

Fig. 1. Forming system of the proposed technique.

Hereafter, the rubber material will push up the floating ring and consequently the blank as well towards the blank holder against the holding spring through the initial gap allocated between the adjustment ring and the blank holder. At the moment when the adjustment ring touches the 
blank holder plate the third step begins in which the forming processing process is terminated under the effect of the punch force and the hydrostatic rubber pressure.

\section{Characterization of Material Behaviors 3.1 Preparation of Tensile Test Specimens}

Chromium-nickel stainless steel 304 foils (SS 304), which its chemical composition is illustrated in Table 1, with initial thickness of $100 \mu \mathrm{m}$ are used in this study for process workpieces. The many advantages of stainless steel 304 such as anticorrosion and lifetime of products make the fabrication and industrial applications of SS 304 sheets remarkably increases [3].

Table 1,

Chemical composition of stainless steel 304 sheet metal.

\begin{tabular}{lllll}
\hline $\mathbf{C r}$ & $\mathbf{M n}$ & $\mathbf{N i}$ & $\mathbf{C}$ & $\mathbf{F e}$ \\
\hline $17-20 \%$ & $<2 \%$ & $8-11 \%$ & $<800$ & Balance \\
\hline
\end{tabular}

The effect of the anisotropic behaviour (due to the rolling operation) of the SS 304 foil are evaluated here through cutting dogbone-shaped specimens along rolling, diagonal $\left(45^{\circ}\right)$ and transverse directions. The dimensions for the dogbone specimens are obtained from the ASTM E8 [12] standard as shown in Figure 2a.

However, the very thin stainless steel sheets are very difficult to cut directly using traditional methods and tools as they may fold through handling and cutting or rough cut edges may be obtained. To solve this problem, the stainless steel sheet is clamed between two Perspex plates of $1 \mathrm{~cm}$ thickness and the cutting operation is then carried out. High attention is paid for that area near the cutting edge where number of fasteners are specifically fixed at this area to ensure additional support to prevent relative shaking as explained in Figure 2b. The specimens of SS 304 are cut by using CNC cutter machine from C-tek Company with spindle velocity equal to $2500 \mathrm{rpm}$ and cutter tool with $2 \mathrm{~mm}$ diameter, as shown in Figure 2c.

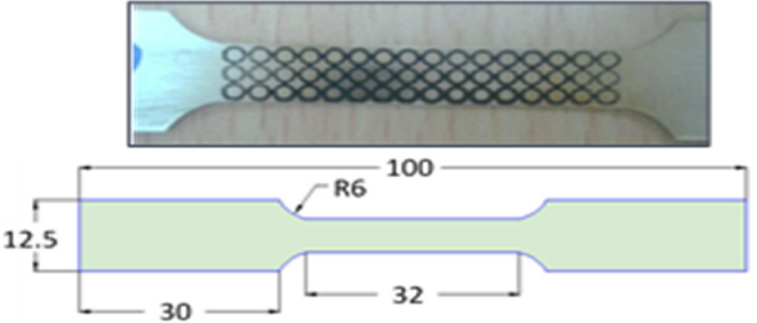

(a)

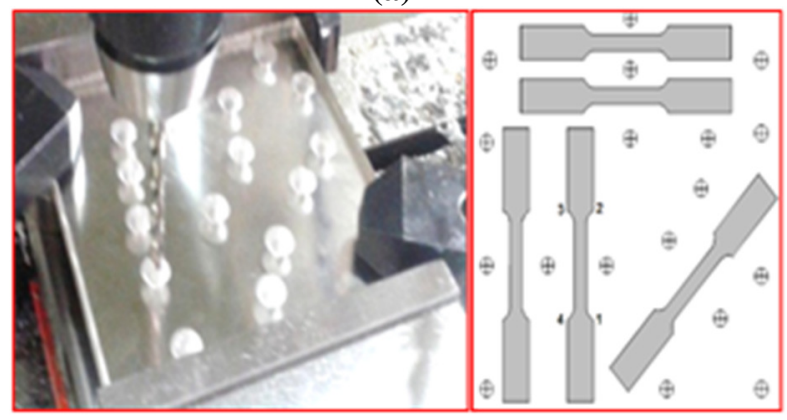

(b)

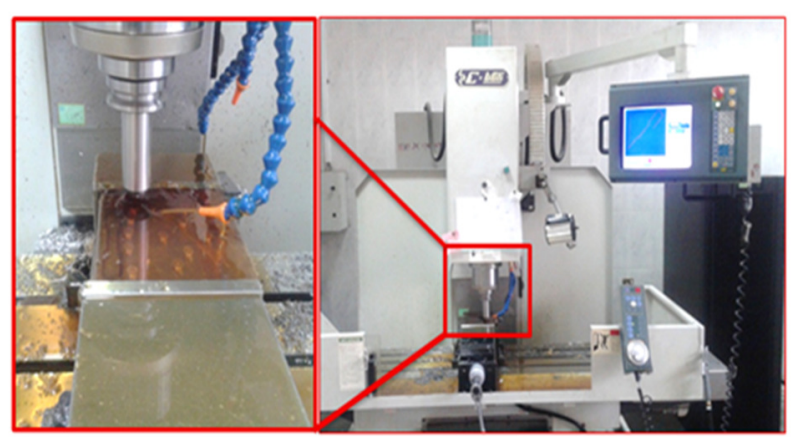

(c)

Fig. 2. (a) Dogbone sample (b) Drilling system (c) Cutting process of dogbone samples.

\subsection{Tensile Test of SS 304 Material}

The tensile tests of SS 304 dogbone-shaped specimens are carried out using the universal tensile machine supported by the LARYEE Company to the center of Nano Technology / University of Technology. The load capacity of the LARYEE machine is $100 \mathrm{kN}$ with accuracy +/$0.5 \%$ as shown in Figure 3. The contact conditions between grips surface and specimen surface has a crucial influence on testing results, especially with thin metals. In order to avoid folding the dogbone-shaped specimens of the tensile test, often at the profile radius, it was observed that the friction force at the interface between the grips and specimen should be increased. This action will prevent any probable sliding of the specimen with the surfaces of gripers. Owing to do that, pieces of sand papers were inserted at the specimen/gripers interfaces. 
The tensile test achieved at velocity of $0.2 \mathrm{~mm} / \mathrm{s}$. Through test stroke and at $20 \%$ of total longitudinal strain, a picture is taken for the loaded specimen utilizing a digital camera and this picture is then analyzed by a special software for image processing to evaluate the lateral strain.

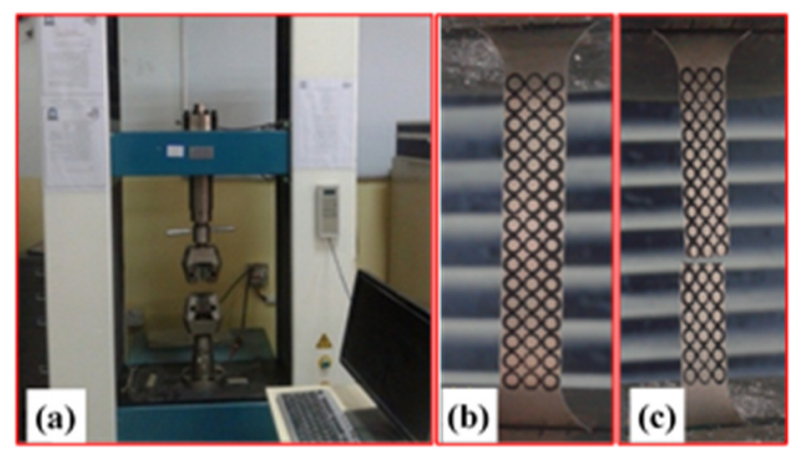

Fig. 3. (a) LARYEE machine (b) Dogbone sample before the test (c) Dogbone sample after the test.

The purpose of this action is to evaluate the lateral strain at this point. Figures 4 and 5 present the engineering and true stress-strain relationships obtained from the tensile tests for the stainless steel 304 foil with $100 \mu \mathrm{m}$ thickness adopted for the forming blanks in this work. The mechanical properties that obtained from tensile test are recorded in Table 2.

Table 2,

Mechanical properties of SS 304 foil.

\begin{tabular}{|c|c|c|c|c|c|c|}
\hline \multicolumn{2}{|c|}{$\begin{array}{l}\text { Thickness } \\
\text { (mm) }\end{array}$} & \multirow{2}{*}{$\begin{array}{l}\mathbf{E} \\
(\mathbf{G P a} \\
194\end{array}$} & \multirow{2}{*}{ 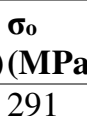 } & \multicolumn{2}{|c|}{$\begin{array}{c}\sigma_{\text {ult }} \\
(\mathbf{M P a}) \\
\varepsilon_{u l t} \%\end{array}$} & \multirow{2}{*}{$\begin{array}{l}\text { K } \\
(\mathbf{M P a}) \\
1213.10 .3708 \\
\end{array}$} \\
\hline \multirow{3}{*}{0.1} & $0^{\circ}$ & & & 540 & 19.51 & \\
\hline & $45^{\circ}$ & 149 & 324 & 62 & 24.86 & 1298.90 .3469 \\
\hline & $\overline{90^{\circ}}$ & 181 & 310 & 622 & 23.20 & 1444.70 .4103 \\
\hline
\end{tabular}

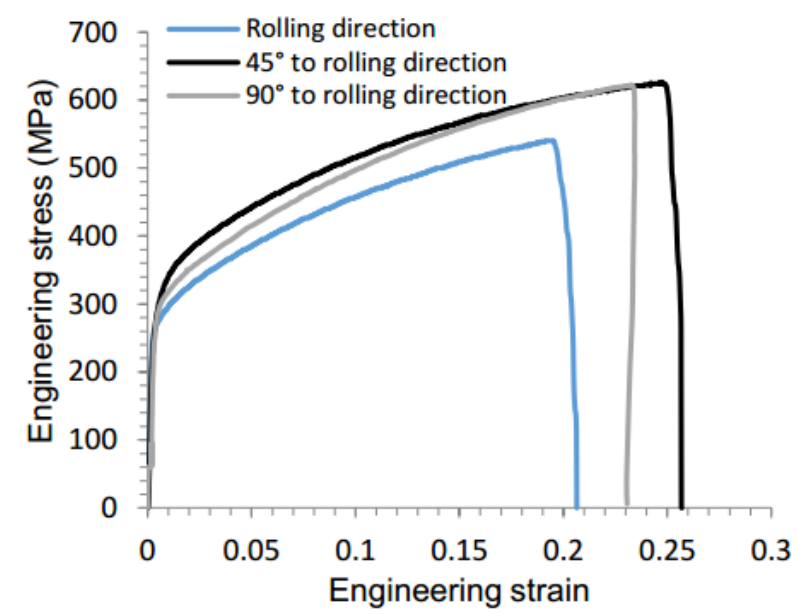

Fig. 4. Engineering Stress-Strain for SS304.

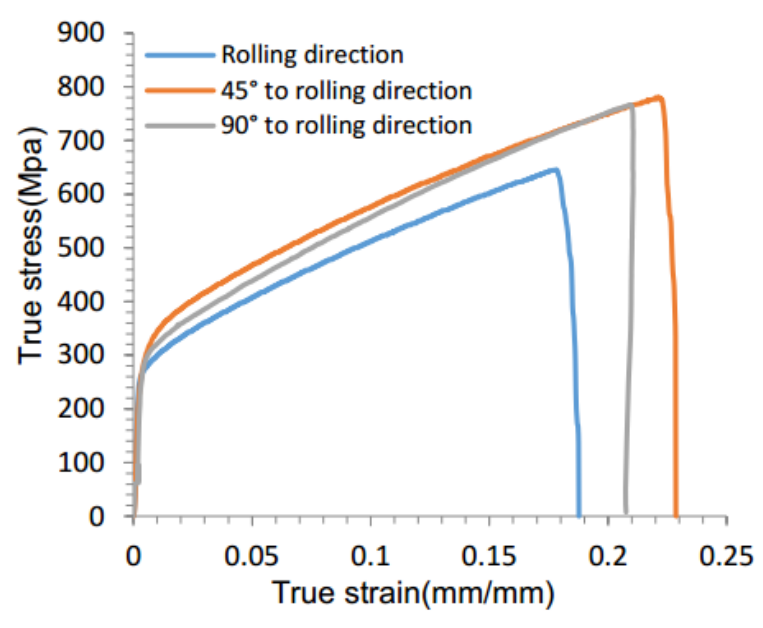

Fig. 5. True Stress-Strain for SS304.

\section{Material Models in FEA Simulation 4.1 Anisotropy of Stainless Steel Foil}

The commercial code Abaqus/Standard software was employed in this study to develop FE simulations for the flexible tool-assisted micro deep drawing. To characterize the deformation behaviour of SS 304 foils, an elastic-plastic model was adopted. To build this model, 8300 elements with mesh type of 8-node linear brick, reduced integration and hourglass control (C3D8R) as shown in Figure 7a. The boundary conditions of blank are at Z- axis direction as XSYMM $(\mathrm{U} 1=\mathrm{UR} 2=\mathrm{UR} 3=0)$ while at $\mathrm{X}$-axis direction as ZSYMM (U3=UR1=UR2=0). The plastic anisotropy is introduced by using Hill's criterion.

$f(\sigma)=\sqrt{\begin{array}{c}\mathrm{F}\left(\sigma_{22}-\sigma_{33}\right)^{2}+\mathrm{G}\left(\sigma_{33}-\sigma_{11}\right)^{2+} \\ \mathrm{H}\left(\sigma_{11}-\sigma_{22}\right)^{2}+2 \mathrm{~L} \sigma_{23}^{2}+2 \mathrm{M} \sigma_{31}^{2} \\ +2 \mathrm{~N} \sigma_{12}{ }^{2}\end{array}}$

the material constants F, G, H, L, M and $\mathrm{N}$ are obtained from tensile tests in different orientations and $\sigma_{i j}$ refers the stress components [13]. These constants are defined as:

$$
\begin{aligned}
& F=\frac{1}{2}\left(\frac{1}{R_{22}^{2}}+\frac{1}{R_{33}^{2}}-\frac{1}{R_{11}^{2}}\right) \\
& G=\frac{1}{2}\left(\frac{1}{R_{33}^{2}}+\frac{1}{R_{11}^{2}}-\frac{1}{R_{22}^{2}}\right) \\
& H=\frac{1}{2}\left(\frac{1}{R_{11}^{2}}+\frac{1}{R_{22}^{2}}-\frac{1}{R_{33}^{2}}\right) \\
& L=\frac{3}{2 R_{23}{ }^{2}} \quad M=\frac{3}{2 R_{13}{ }^{2}} \quad N=\frac{3}{2 R_{12}{ }^{2}}
\end{aligned}
$$

the factors $R_{11}, R_{22}, R_{33}, R_{12}, R_{13}$ and $R_{23}$ are anisotropic yield stress ratios. Due to the stress situation in sheet metal forming processes are characterized by plane stress conditions therefore 
four anisotropic ratios are considered in this work which are $R_{11}, R_{22}, R_{33}$ and $R_{12}$ [14]. In Abaqus software, these factors are expresses using Lankford Factors as $r_{0}, r_{45}$ and $r_{90}$ as following equations [15]:

$\mathrm{R}_{22}=\sqrt{\frac{\mathrm{r}_{90}\left(\mathrm{r}_{\mathrm{o}}+1\right)}{\mathrm{r}_{\mathrm{o}}\left(\mathrm{r}_{90}+1\right)}} \quad \mathrm{R}_{33}=\sqrt{\frac{\mathrm{r}_{90}\left(\mathrm{r}_{\mathrm{o}}+1\right)}{\mathrm{r}_{\mathrm{o}}+\mathrm{r}_{90}}}$

$\mathrm{R}_{12}=\sqrt{\frac{3 \mathrm{r}_{90}\left(\mathrm{r}_{\mathrm{o}}+1\right)}{\left(2 \mathrm{r}_{45}+1\right)\left(\mathrm{r}_{\mathrm{o}}+\mathrm{r}_{90}\right)}}$

where $r_{0}, r_{45}$ and $r_{90}$ are width strain to thickness strain ratios of the work-piece material at the rolling, diagonal and transverse directions, respectively. The values of (r) and (R) of SS 304 sheets employed in the current work are calculated using the above equations, as shown in Table 3.

Table 3,

Plastic strain ratios and anisotropic yield stress ratios.

\begin{tabular}{lcccc}
\hline $\begin{array}{c}\text { Rolling } \\
\text { direction }\end{array}$ & $\begin{array}{c}\text { Eng. } \\
\text { Length } \\
\text { strain }\end{array}$ & $\begin{array}{c}\text { Eng. } \\
\text { Width } \\
\text { strain }\end{array}$ & $\begin{array}{c}\text { Thickness } \\
\text { strain }\end{array}$ & $\begin{array}{c}\text { plastic strain } \\
(\mathbf{r})\end{array}$ \\
\hline $0^{\circ}$ & 0.2 & -0.40 & 0.6931472 & 0.73696559 \\
\hline $45^{\circ}$ & 0.2 & -0.69 & 1.3535045 & 0.86529668 \\
\hline $90^{\circ}$ & 0.2 & -0.44 & 0.7621401 & 0.76077683 \\
\hline
\end{tabular}

\begin{tabular}{llll}
\hline R11 & R22 & R33 & R12 \\
\hline
\end{tabular}

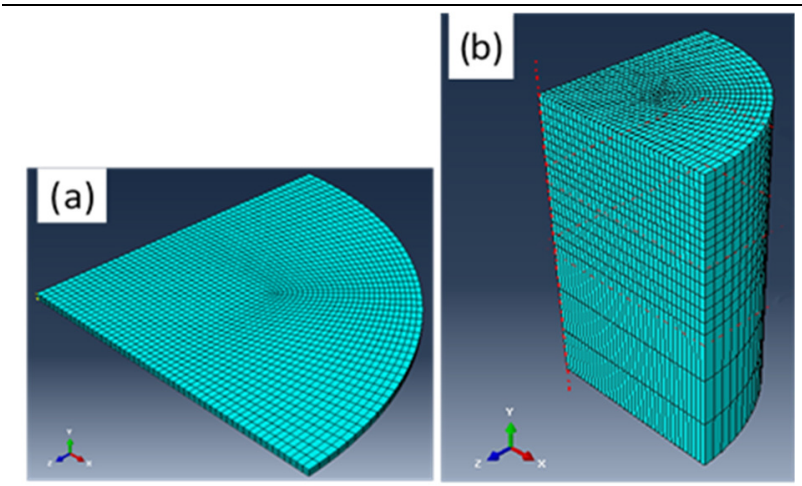

Fig. 7. (a) FE model of SS 304 blank (b) FE model of flexible pad.

\subsection{Hyper-Elastic Model for Rubber Pad Material}

To describe the behaviour of the polyurethane rubber used for the flexible die, the known Mooney-Rivlin hyperelastic model is adopted in the FE model. It is known that polyurethane rubber is characterized by a nonlinear stressstrain relation for large deformation, as well as it is nearly incompressible. The strain energy form of Mooney-Rivlin is:

$\mathrm{W}=\mathrm{C}_{10}\left(\mathrm{I}_{1}-3\right)+\mathrm{C}_{01}\left(\mathrm{I}_{2}-3\right)+\left(\mathrm{J}_{1}-1\right) / \mathrm{D}_{1}$

where $\mathrm{W}$ is the strain energy per unit of volume, $I_{1}$ and $I_{2}$ are the strain invariants, $J$ is volume change. $\mathrm{C}_{10}$ and $\mathrm{C}_{01}$ describe hyperelastic rubber deformation, and $\mathrm{D}_{1}$ indicates the material compressibility [16]. The deformation behavior of rubber material was described by using hyperelastic model. This part has 13806 elements with mesh type 8-node linear brick, hybrid, constant pressure, reduced integration and hourglass control (C3D8RH). The mechanical properties of the polyurethane rubber 55 Shore A hardness are presented in Table 4 [17].

Table 4,

Mechanical properties of Polyurethane rubber materials.

\begin{tabular}{llll}
\hline $\begin{array}{l}\text { Hardness } \\
\text { Shore A }\end{array}$ & $\begin{array}{l}\text { M-R constant M-R constant Poisson's } \\
\text { C10 }(\mathbf{M P a})\end{array}$ & $\mathbf{C 0 1}(\mathbf{M P a})$ & ratio (v) \\
\hline 55 & 0.382 & 0.096 & 0.4999 \\
\hline
\end{tabular}

The process geometry dimensions adopted in this study are listed in Table 5 . The coefficients of friction adopted at the different contact interfaces in the finite element models are presented in Table 6.

Table 5,

Geometrical parameters of flexible micro deep drawing model.

Parameters Value(mm)

Blank diameter 10

Blank thickness 0.1

Punch diameter 4

Radius of punch corner $\quad 0.8$

Height of rubber pad 10

Diameter of rubber pad $\quad 12$

Thickness of flat floating ring 1

Diameter of floating ring 13

Radius of inner corner of floating ring $\quad 0.75$

Table 6,

Coefficients of friction adopted at different interfaces.

\begin{tabular}{ll}
\hline Interface & $\begin{array}{l}\text { coefficient of } \\
\text { friction }\end{array}$ \\
\hline Blankholder / blank & 0.1 \\
Floating ring / blank & 0.05 \\
Rubber pad / blank & 0.1 \\
Punch / blank & 0.25 \\
Floating ring / rubber pad & 0.05 \\
adjustment ring / blankholder & 0.05 \\
\hline
\end{tabular}




\section{Experimental Set Up}

To conduct micro deep drawing experiments under that conditions a special device is required to be manufactured with accuracy level meets the operation requirements. The device consists from three main groups of parts; the first group includes the movable parts and the second includes fixed parts, then the floating part as shown in Figure 8.

The movable group involves in turn two subgroups, the first one consists of rigid punch and punch plate, while the second one consists of middle plate, blankholder, blankholder house, adjustment ring, three adjustment studs and holding spring. The rigid punch has a threated head at which it is attached to the punch plate and both of them connect to the compression machine grip through a span. The blank holder house and middle plate are connected together using three studs. The other function of these three studs is to adjust the distance between blank holder and middle plate from a side and the distance between the blankholder house and the adjustment ring from another side. The last distance actually represents the initial gap, mentioned in Figure 1, through which the blankholder move up just against the holding spring force. The second main group, i.e fixed parts, consists of the heavy base of the device, three guides, rubber pad house and the upper ring. The rubber pad material that manufactured by PAR Group Ltd. in the UK with grade 55 Shore A has geometrical properties as the height equal to $10 \mathrm{~mm}$ and $12 \mathrm{~mm}$ as diameter. The difference between the height of rubber container and rubber pad equal to $5 \mathrm{~mm}$, through this space the floating ring will be placed and the remaining space is for the blankholder. The last component of the device developed for the current experiments is the floating ring which represents the novel point of this research. The dimensions of flat floating ring are the thickness equal to $1 \mathrm{~mm}$ and the outer, inner diameters equal to $12 \mathrm{~mm}$ and $4.24 \mathrm{~mm}$, respectively and the inner hole has edge curvature equal to $0.75 \mathrm{~mm}$.

\section{Experiment Procedure}

In micro sheet metal forming, the blanking operation has high importance as it is represented a crucial action on which the success of micro forming process significantly depends. To carry out blanking process, a set of punch /die tool with specific dimensions is utilized. The most important parameter in any sheet blanking operation is the clearance between the punch and die. In order for high quality cutting process, a clearance of about 12-24\% of the initial foil thickness should be adopted for the punch/die set [4]. Thus, the blanking tools used in the current work were designed and manufactured with clearance of $20 \%$ which means approximately 20 $\mu \mathrm{m}$ (see Figure 9).

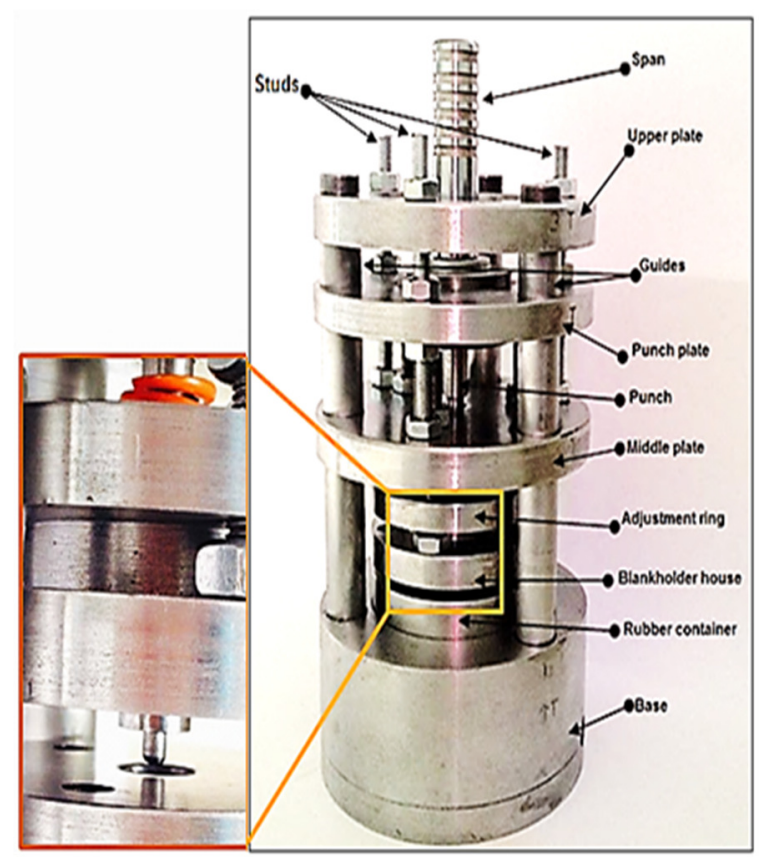

Fig. 8. Flexible too-assisted micro deep drawing device.

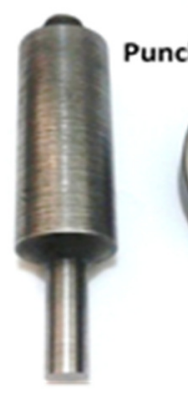

(a)
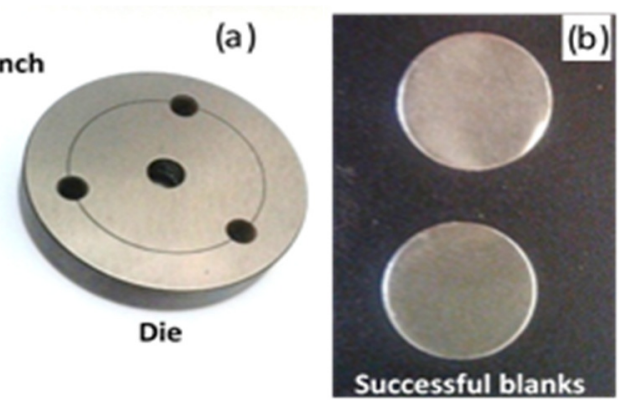

Fig. 9. (a) Blanking tools (b) Blanks of SS304 with $10 \mathrm{~mm}$ diameter.

The flexible micro forming experiments were implemented using LARYEE machine which has the load capacity equal to $100 \mathrm{kN}$ with accuracy $+/-0.5 \%$. To start the experimental procedure, firstly an initial gap is adopted very carefully and accurately between the adjustment ring and the blankholder house. Thereafter, the outer studs are tightened on the upper plate and let the punch plate free at this step. Through this procedure will permit more support to the device during the 
forming process. The next step is to insert the floating ring onto the rubber pad die and then insert the blank over the floating ring and ensuring from it's in the correct position.

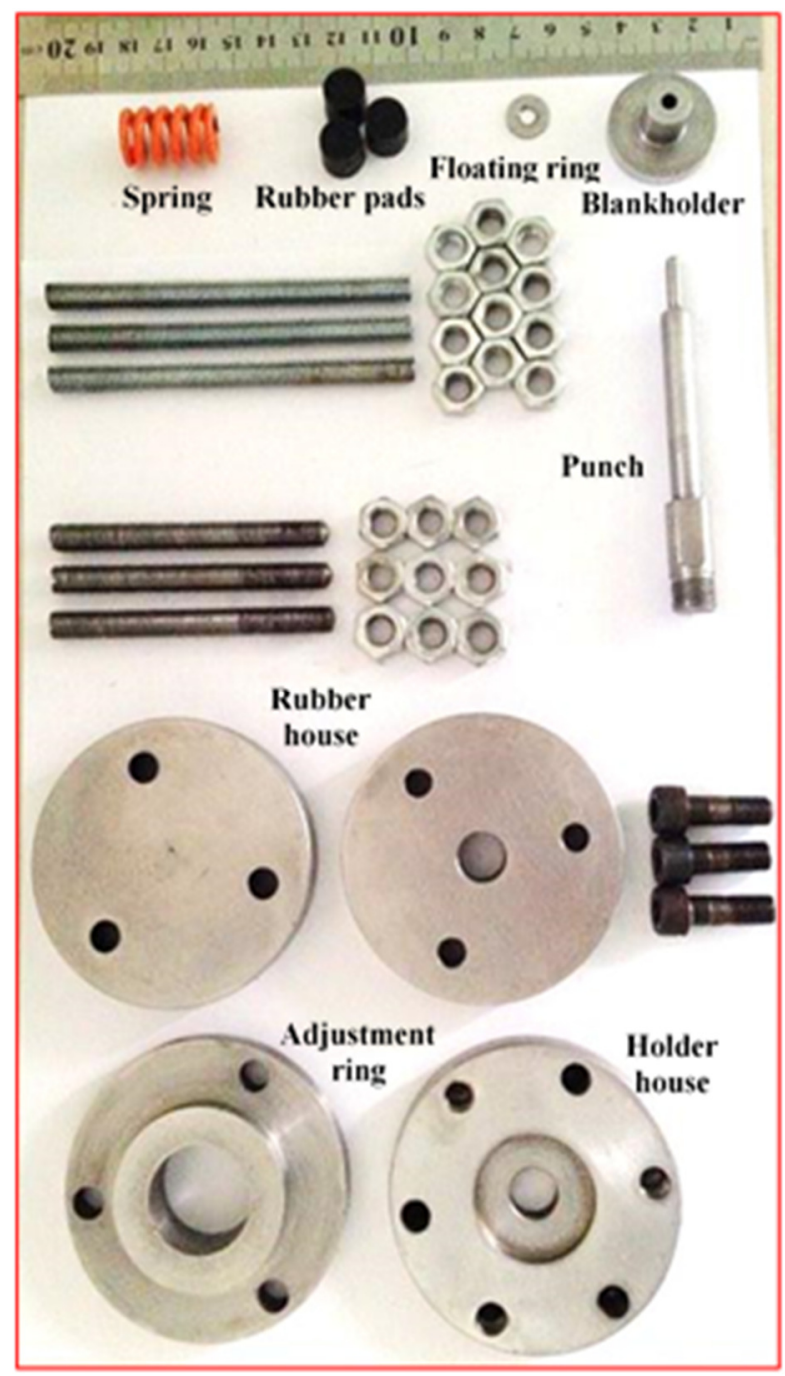

Fig. 10. Components of device.

Now, the device ready to setup on the universal machine and attach the upper span to the machine grips. The forming was done with $1 \mathrm{~mm} / \mathrm{s}$ as forming speed until reaching the specified depth. Figure 10 shows the components utilized in the micro forming operation.

\section{Results and Discussions}

The crucial parameter of evaluating the product quality is the thickness distribution along the entire cup wall. Therefore, a homogenous thickness distribution of the product represents indication of good quality. Therefore, a special technique required to obtain good cutting process.
In this study, we used the Epoxy liquid which mixed carefully with its hardener. Thereafter, the solid system is extracted from the die. Now, the cup is ready for cutting process. The cutting process was done by using mechanical cutter machine with blade cutter thickness equal to $0.1 \mathrm{~mm}$. To obtain a good status of edge of cup, the cut face is polished using very fine sand paper. Figure 11 shows the section of epoxy and metallic cup cut along the rolling direction. After that, the thickness distributed along wall cup was evaluated by using microscope machine to determine the real value the thickness at every point of wall cup.

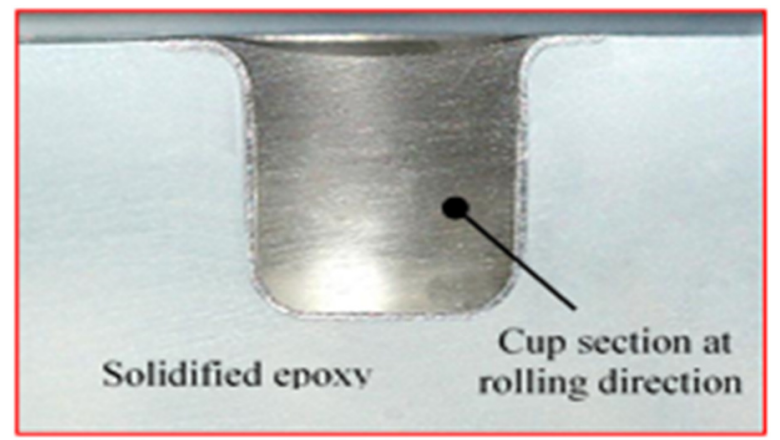

Fig. 11. Section of epoxy material and metallic cup.

\subsection{Thickness Distribution}

This section includes the results that obtained from the experiments of micro deep drawing and validate these results with that obtained by FE simulation under the corresponding conditions. In this study, there are two parameters studied for one case such as thickness distribution and loaddisplacement relation. To study these parameters, the conditions that adopted in the experiments procedure were as following: punch diameter was $4 \mathrm{~mm}$ with head radius $0.8 \mathrm{~mm}$, Rubber pad diameter was $12 \mathrm{~mm}$ with height $10 \mathrm{~mm}$, initial blank thickness $0.1 \mathrm{~mm}$ with $10 \mathrm{~mm}$ as diameter, floating ring thickness was $1 \mathrm{~mm}$ with shoulder radius $0.75 \mathrm{~mm}$ and forming velocity was $1 \mathrm{~mm} / \mathrm{s}$. Among these parameters the initial gap that adopted has a crucial effect on the forming process. The unsuitable gap distance leads to failure the product as shown in FE simulations. Figure 13 shows the cups obtained from micro deep drawing experiments. Firstly the fracture part, as mentioned above the gap value has a crucial effect so that at this case due to gap distance very small, the fracture occurred. This type of failure was verified through FE simulation for the same reason in Figure 12. 

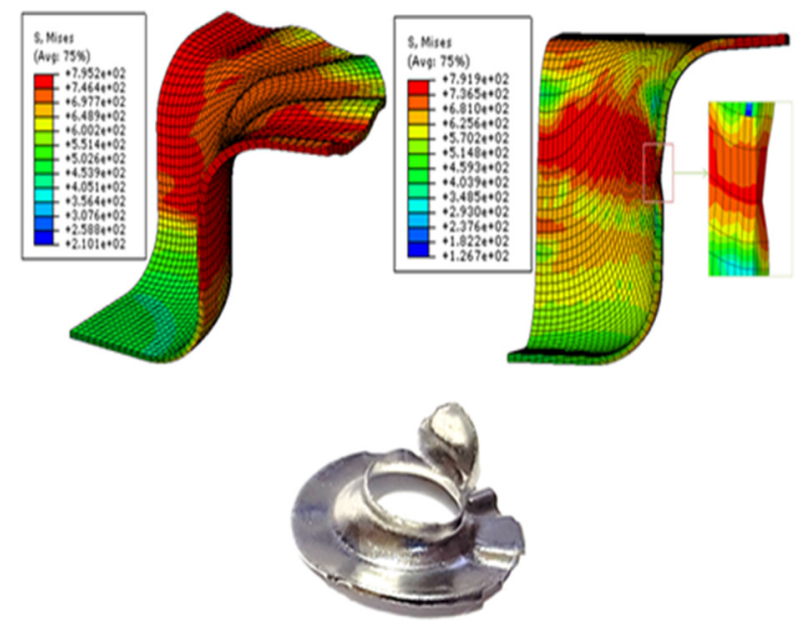

Fig. 12. Comparison the failure cups through simulation and experiment drawing.

On the other hand, micro cups with wrinkling was obtained when the adopted gap is greater than the optimum one, this action allow for the blank to deform freely for longer time through the deeper gap without supporting force. The folds appear firstly at the flange portion and then move along to cup-side wall gradually with the forming stroke. Also, this type of failure was verified by FE simulation as shown in Figure 12. Afterward, great efforts were done to adjust the appropriate gap which finally found to be $0.2 \mathrm{~mm}$ for the conditions taken into account to produce successful cups as shown in Figure 13.

The Figures 14 and 15 presented a comparison of thickness distributions of wall cup for simulation and experimental. The results showed well match of the results that obtained by simulation and experimental along rolling and transverse directions. This indicate to the results that obtained by experimental agree with the predictions of simulation results. The maximum thinning occur at profile radius region for both simulation and experiment along rolling and transverse directions. After that, the tendency of thinning disappeared at side wall region and the thickness of wall increased gradually to be thickening at the upper part of side wall. In general, the thickening trend continued until reaching the maximum value at the ending part of shoulder radius region. Then, the thickening decreased along flange portion. For more realization, Figure 16 present percentage of maximum thinning that occur for both simulation and experimental results along rolling and transverse directions.

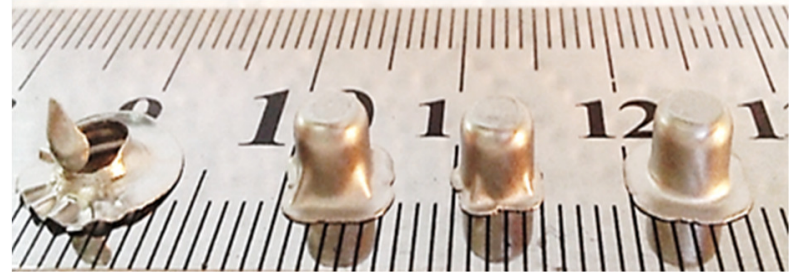

Fig. 13. Physical micro formed cups.

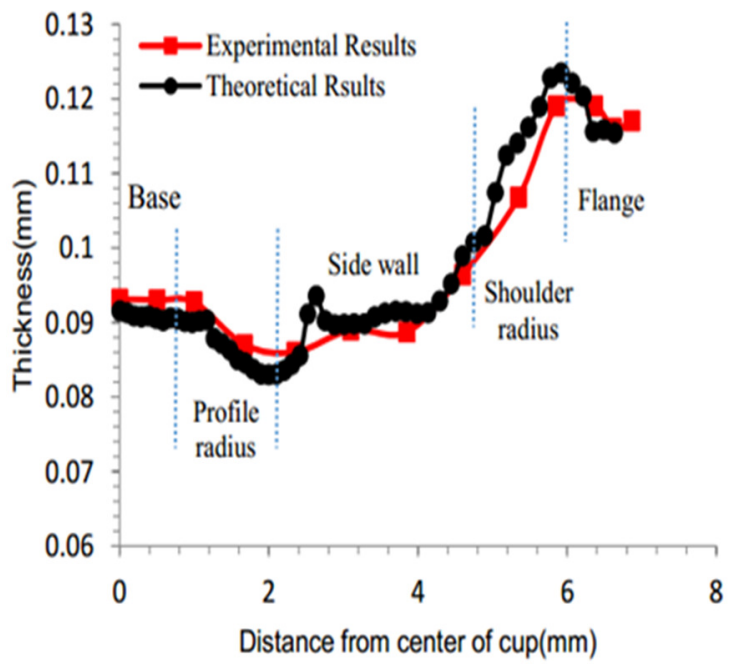

Fig. 14. Thickness distributions of wall cup at rolling direction.

The maximum thinning was $17 \%$ along rolling direction of physical cup. While, the simulation result revealed decreasing the tendency of thinning to be $14 \%$. On other side, the transverse direction don't display a significant thinning variation between the simulation and experimental results. Where the maximum thinning was $13.44 \%$ for simulated cup while $13 \%$ for physical cup. 


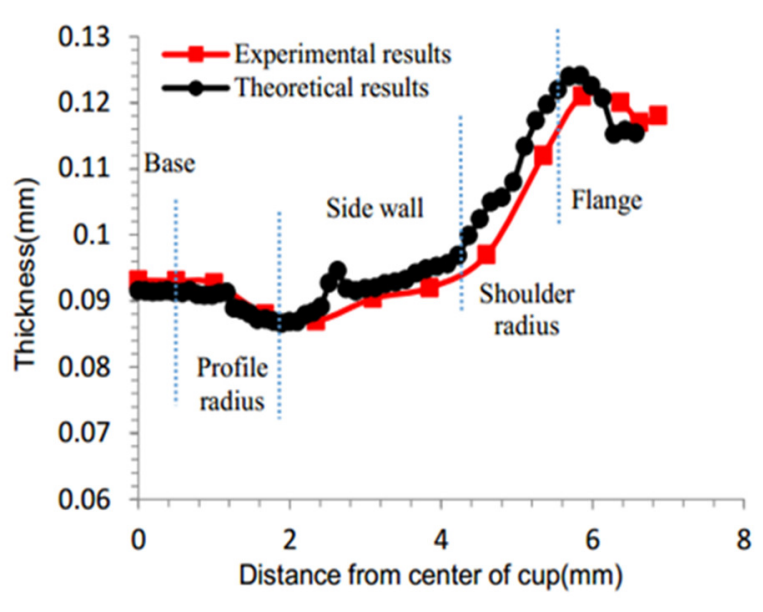

Fig. 15. Thickness distributions of wall cup transverse direction.

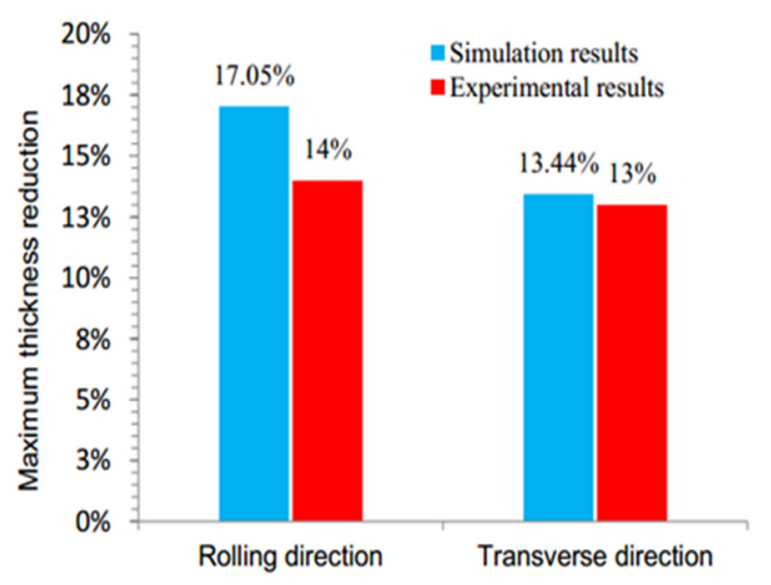

Fig. 16. Maximum thickness reduction.

\subsection{Load-Displacement Relationship}

Figure 17 present the relation between load and displacement of punch for both simulation and experimental of cup drawing. In general, the curves showed the same trend during the forming process until reaching the maximum value of load. Firstly, the experiment curve showed increasing dramatically due to the forming tools are initially in contact with them which lead to make the force required higher than that obtained by simulation. Although, the experiment curve is higher than that obtained by FE simulation. But, the last step revealed the experiment load decreased to be less than that predicted by FE simulation. This effect may be due to the rubber container diameter is relatively greater than as adopted in simulation model that lead to expanding the rubber in radial direction.

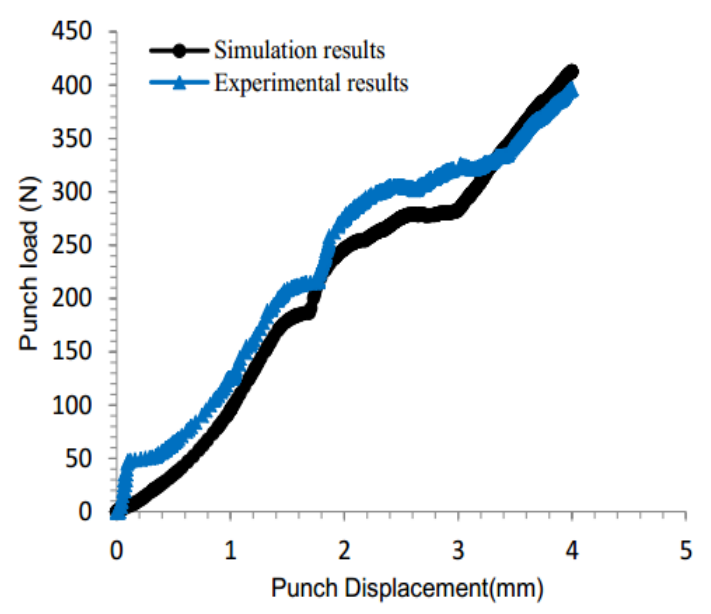

Fig. 17. Comparison punch load-displacement relation for both simulation and experiment.

The difference between these curves due to the experimental difficulty to determining the coefficient of friction between the interfaces of forming tools. Also, the device of experiment drawing consist of different parts have a contact between them. All these parameters may be lead to the experiment load higher than that obtained by simulation drawing. The maximum load that obtained by simulation was $412.35 \mathrm{~N}$ while the experiment load was $396.47 \mathrm{~N}$. On other side, the novel proposed technique revealed the feasibility to produce micro cups with aspect ratio higher than unity through one stroke of forming.

The results that obtained by simulation process to produce cups with aspect ratio 1.25 are validated by experiment process. The same conditions that adopted in simulation process are used in the process of experiment. The physical cup showed a good correlation with that predicted by simulation in term of geometrical profile. Also, it can denote that there is a good matching between the two parts in term of the effect of anisotropic behavior of SS304 sheet metal. Figure 18 presents a comparison between the simulation and physical parts.

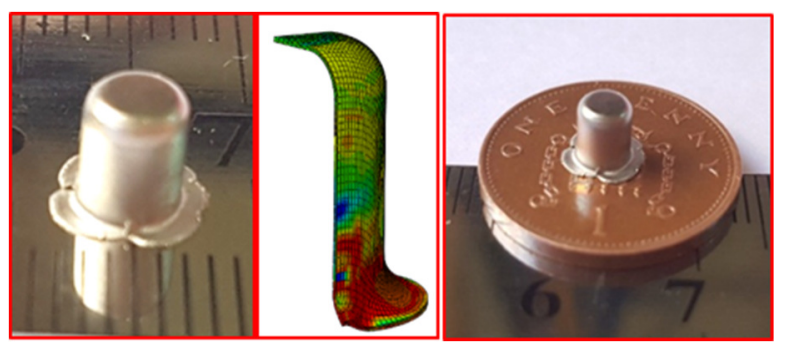

Fig. 18. Comparison between physical and simulated cups that have aspect ratio 1.25 . 


\section{Conclusion}

The current study presents a novel technique for micro deep drawing of stainless steel 304 cups through using a floating ring concept with the technology of flexible tool. An experiments and FE simulations were achieved to validate the feasibility of the proposed technique. The forming procedure starts with adopting a particular initial gap the blank holder and the adjustment ring. This gap allows for all of blank, blankholder and floating ring to move up just against the force of holding spring under the effect of the hydrostatic pressure excited in the rubber material-die. Basically, the main function of the floating ring part is to define the dimension of the required product at the profile radius as well as to work as an assistant die allowing for the blank to form initially without rubber pad-excited hydrostatic pressure for a partial period of the whole forming stroke. The important finding here is that the current technique exhibits a clear role in reducing the influence of the anisotropic behaviour of SS 304 sheet on the thickness distribution of formed cups. It was observed that using the technique of floating ring results in reducing the maximum external load required to complete the forming stroke compared with the results obtained by I. Irthiea. Another finding is that a good correlation between the simulations and the experimental results was obtained. This study proved the capability of the new technique to be adopted for prototyping micro forming processes. Moreover, the study revealed the feasibility of the proposed technique for producing micro cups with remarkable application flexibility in miniaturization technology as micro cups with relatively high aspect ratio of 1 and 1.25 through just a single micro forming stage.

\section{References}

[1] Y. M. Huang \& Y. S. Wu \& J. Y. Huang, "The influence of ultrasonic vibrationassisted micro-deep drawing process", International Journal of Advanced Manufacture Technology, (2014) 71:14551461.

[2] Masoomeh Salahshoor \& Abdolhamid Gorji and Mohammad Bakhshi- Jooybari, "The study of forming concave-bottom cylindrical parts in hydroforming process", International Journal of Advanced Manufacture Technology, (2015) 79:1139-1151.
[3] Ihsan Irthiea, Graham Green, Safa Hashim and Abdulbast Kriama, "Experimental and numerical investigation on micro deep drawing process of stainless steel 304 foil using flexible tools", International Journal of Machine Tools \& Manufacture, (2014) 76:21-33.

[4] Ihsan K. Irthiea and Graham Green, "Evaluation of micro deep drawing technique using soft die-simulation and experiments", International Journal of Advanced Manufacture Technology, (2017) 89:23632374.

[5] Quadrini F, Santo L, Anna E (2010) Flexible forming of thin aluminum alloy sheets. Int $\mathbf{J}$ Mod Manuf Technol, II: 79-84.

[6] Balasubramanian Nagarajan, Sylvie Castagne, Zhongke Wang, H.Y. Zheng and Kartikeyan Nadarajan, "Influence of plastic deformation in flexible pad laser shock forming - experimental and numerical analysis", International Journal of material forming, 1-15.

[7] Liu Y, Hua L, Lan J, Wei X, "Studies of the deformation styles of the rubber-pad forming process used for manufacturing metallic bipolar plates", J Power Sources, (2010) 195:8177-8184.

[8] C. Kyu, M. Geun, and C. Gil, "Effect of rubber forming process parameters on micropatterning of thin metallic plates," Procedia Eng., vol. 81, pp. 1439-1444, 2014.

[9] Wang X, Du D, Zhang H, Shen Z, Liu H, Zhou J, Liu H, Hu Y, Guc, "Investigation of microscale laser dynamic flexible forming process-simulation and experiments", International Journal of Machine Tools \& Manufacture, (2013) 67:8-17.

[10] X. Ma, R. Lapovok, C. Gu, A. Molotnikov, Y. Estrin, E. V. Pereloma, C. H. J. Davies and P. D. Hodgson, "Deep drawing behaviour of ultrafine grained copper: modelling and experiment", Journal of Material sience, vol. 44, pp. 3807-3812, 2009.

[11] R. Lapovok, I. Timokhina, P. W. J. Mckenzie and R. O'donnell, "Processing and properties of ultrafine-grain aluminium alloy 6111 sheet", Journal of Materials Processing Technology, vol. 200, pp. 441450, 2008.

[12] American Society for Testing and Materials ASTM, "Standard Test Methods for Tension Testing of Metallic Materials," Am. Assoc. State, pp. 1-27, 2010. 
[13] Le Port A, Toussaint F and Arrieux R, "Finite element study and sensitive analysis of the deep drawing formability of commercially pure titanium". International Journal of material forming, (2009) 2:121129.

[14] D.V. Hai, S. Itoh, T. Sakai, S. Kamado, Y. Kojima,"Experimentally and numerical study on deep drawing process for magnesium alloy sheet at elevated temperatures", Materials Transactions, (2008) 49:1101-1106.

[15] Ihsan Khalaf Irthiea, "Process Analysis and Design in Micro Deep Drawing Utilizing a Flexible Die," University of Glasgow, 2014.
[16] L. Crocker and B. Duncan, "Measurement methods for obtaining volumetric coefficients for hyperelastic modelling of flexible adhesives", Performance of Adhesive Joints Program, Project PAJex2 Flexible Adhesives, PAJex2 Report No 3.

[17] Linfa Peng, Peng Hu, Xinmin Lai, Deqing $\mathrm{Mei}$, Jun $\mathrm{Ni}$, "Investigation of micro/ meso sheet soft punch stamping processsimulation and experiments", Materials \&Design, (2009) 30:783-790. 


\title{
تحقيق عملي ومحاكاة لعملية سحب عميق مايكروية بأدوات مرنة بأستخدام تقنية الحلق الطافي
}

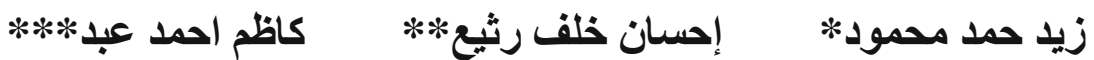

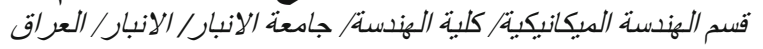

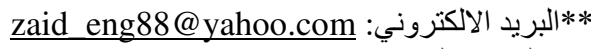 \\ ih77san@yahoo.co.uk البريد الالكتروني:***
}

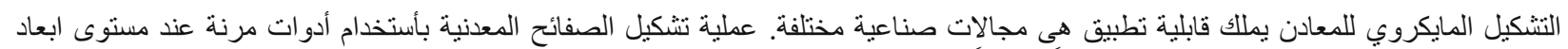

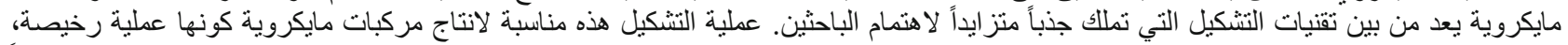

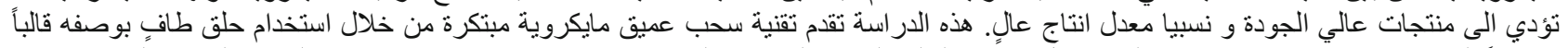

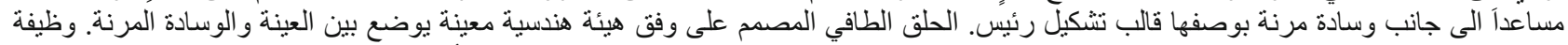

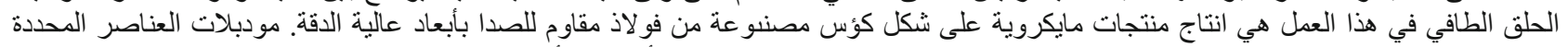

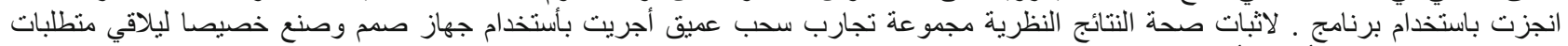
الموديل النظري. بالنتائج أثنتت بأن التقنية المقترحة في هذه الدر اسة هي ذات جدوى لانتاج منتجات مايكروية التي تملك امكانية تطبيق عالية في التنكنولوجية لنية 